\title{
NIMBUS-7 SMMR DERIVED GLOBAL SNOW COVER PARAMETERS
}

by

\author{
A.T.C. Chang, J.L. Foster and D.K. Hall
}

(Hydrological Sciences Branch, NASA/Goddard Space Flight Center, Greenbelt, MD 20771, U.S.A.)

\section{ABSTRACT}

Snow covers about 40 million $\mathrm{km}^{2}$ of the land area of the Northern Hemisphere during the winter season. The accumulation and depletion of snow is dynamically coupled with global hydrological and climatological processes. Snow covered area and snow water equivalent are two essential measurements. Snow cover maps are produced routinely by the National Environmental Satellite Data and Information Service of the National Oceanic and Atmospheric Administration (NOAA/NESDIS) and by the US Air Force Global Weather Center (USAFGWC). The snow covered area reported by these two groups sometimes differs by several million $\mathrm{km}^{2}$. Preliminary analysis is performed to evaluate the accuracy of these products.

Microwave radiation penetrating through clouds and snowpacks could provide depth and water equivalent information about snow fields. Based on theoretical calculations, snow covered area and snow water equivalent retrieval algorithms have been developed. Snow cover maps for the Northern Hemisphere have been derived from Nimbus-7 SMMR data for a period of six years (1978-1984). Intercomparisons of SMMR, NOAA/NESDIS and USAFGWC snow maps have been conducted to evaluate and assess the accuracy of SMMR derived snow maps. The total snow covered area derived from SMMR is usually about $10 \%$ less than the other two products. This is because passive microwave sensors cannot detect shallow, dry snow which is less than $5 \mathrm{~cm}$ in depth. The major geographic regions in which the differences among these three products are the greatest are in central Asia and western China. Future study is required to determine the absolute accuracy of each product.

Preliminary snow water equivalent maps have also been produced. Comparisons are made between retrieved snow water equivalent over large area and available snow depth measurements. The results of the comparisons are good for uniform snow covered areas, such as the Canadian high plains and the Russian steppes. Heavily forested and mountainous areas tend to mask out the microwave snow signatures and thus comparisons with measured water equivalent are poorer in those areas.

\section{INTRODUCTION}

Remotely acquired microwave data in conjunction with essential ground observations will most likely lead to advanced extraction of snow properties beyond conventional techniques. Landsat visible and near-infrared data have recently become near operational for use in measurements of snow covered areas (Rango 1975, 1978). Operational NOAA satellites provide continuous global coverage with $4 \mathrm{~km}$ spatial resolution. Both Landsat and NOAA data acquisition are hampered by cloud cover, sometimes at critical times when a snowpack is ripe and ready to melt. Furthermore, information on water equivalent, free water content and other snowpack properties germane to accurate snow melt run-off prediction is not currently available using visible and near-infrared data because only surface and near surface snow contribute to the measured reflectances.

Microwave remote sensors which have the capability to penetrate the snowpack and respond to variations in snow properties, could provide information about snow depth and snow water equivalent (Rango and others 1979; Chang and others 1982). However, due to the coarse spatial resolution of the present microwave radiometers, combinations of vegetation, terrain and snow information within a pixel greatly complicate the retrieval algorithm development.

Algorithms need to be developed that are specific to physiographic areas like the Colorado River basin and the north slope of Alaska. These algorithms will take into account additional parameters related to microwave signatures. Until these algorithms are operational, the use of remotely collected microwave data for global quantitative snowpack analysis will not be operational due to the complexities involved in the data analysis.

\section{MICROWAVE EMISSION FROM SNOW}

Microwave emission from a layer of snow over ground consists of two parts: (1) emission by the snow volume and (2) emission by the underlying ground. Snow particles act as scattering centers for microwave radiation from a snowpack. The scattering effect which redistributes the upwelling radiation according to snow thickness and crystal size, provides the physical basis for microwave detection of snow. Mie scattering theory is used to account for the energy redistribution by snow crystals. Although the snow crystal usually is not spherical in shape, its ensemble scattering properties can be mimicked by spheres (Chang and others 1976). Theoretical computations indicate that scattering by individual snow crystals can be the dominant modification factor of upwelling $37 \mathrm{GHz}(0.8 \mathrm{~cm})$ radiation in the dry snow cases (Chang and others 1982). The effect of scattering is lessened by using the longer wavelengths. Fig.1 shows the calculated brightness temperatures versus snow water equivalent for SMMR frequencies. The effective microwave penetration depth into a dry snowpack, typically 10-100 times the wavelength, depends on the wavelength used and the characteristic crystal size of the snowpack. When the wavelength is much larger than the crystal size $(>5 \mathrm{~cm})$, absorption will be the dominant effect. The brightness temperature will resemble the physical temperature of the snowpack. When the wavelength is comparable to the snow crystal size $(<1 \mathrm{~cm})$, scattering becomes the dominant effect.

Nimbus-7 SMMR is a five-frequency, dual-polarized microwave radiometer which measures the upwelling microwave radiation at $6.6,10.7,18.0,21.0$, and $37.0 \mathrm{GHz}(4.6$, $2.8,1.7,1.4$ and $0.8 \mathrm{~cm}$ ) while scanning $25^{\circ}$ to either side of the spacecraft (approximately $780 \mathrm{~km}$ swath width) with a constant incidence angle of approximately $50^{\circ}$ with respect to the Earth's surface. The spatial resolution varies from $25 \mathrm{~km}$ for the $37 \mathrm{GHz}(0.8 \mathrm{~cm})$ to $150 \mathrm{~km}$ for the $6.6 \mathrm{GHz}$ $(4.6 \mathrm{~cm})$. A detailed description of this instrument can be found in Gloersen and Barath (1977). The Nimbus-7 satellite was launched on October 24, 1978, into a sun-synchronous polar orbit with local noon/midnight equatorial crossing.

Using the multifrequency analysis approach, one may make inferences regarding not only the thickness of the snowpack, but the underlying soil (wet versus dry) condition. The shorter wavelengths, such as $0.8 \mathrm{~cm}(37 \mathrm{GHz})$, sense near surface $(0-50 \mathrm{~cm})$ temperature and emissivity, and 


\section{CALCULATED BRIGHTNESS TEMPERATURE AS A FUNCTION OF SNOW WATER EQUIVALENT (HORIZONTAL POLARIZATION, $\theta=50^{\circ}$, FROZEN GROUND)}

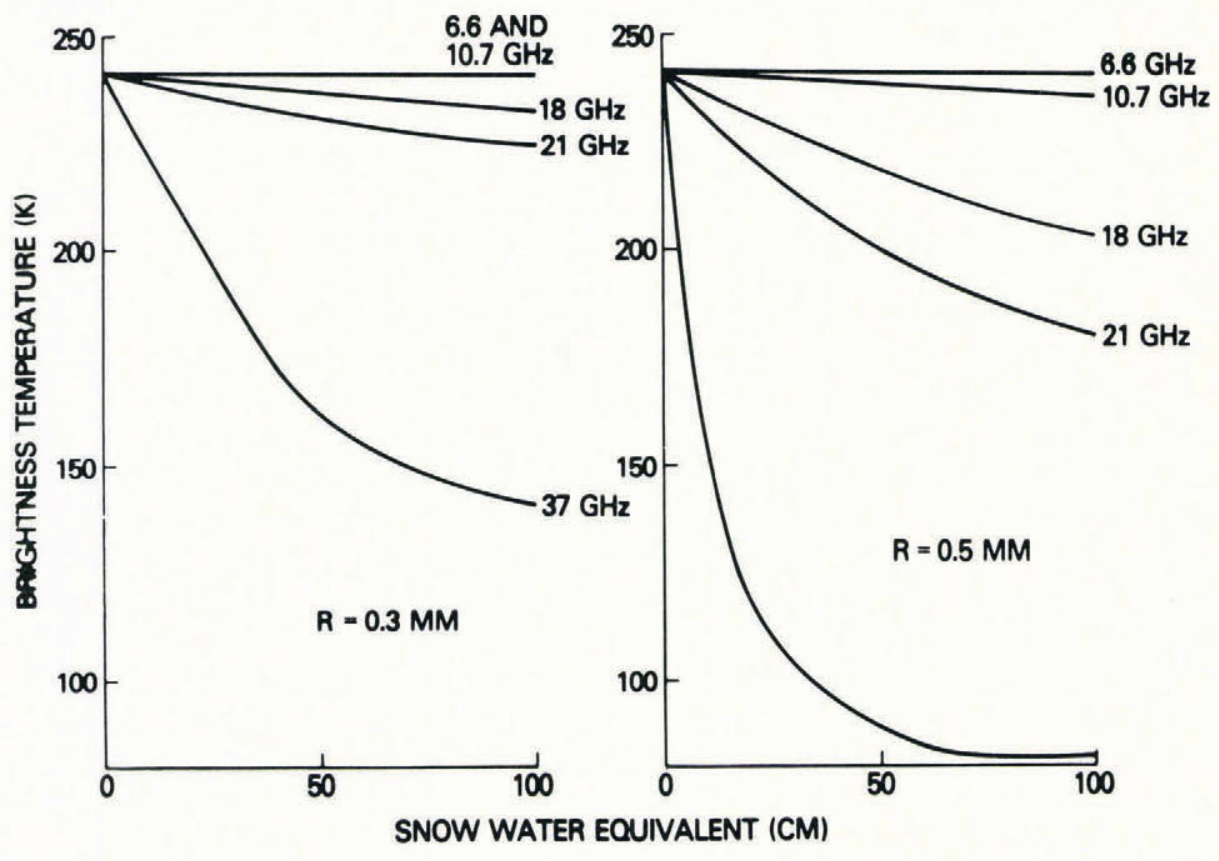

Fig.1. Calculated brightness temperatures versus snow water equivalent for five SMMR frequencies with horizontal polarization and $50^{\circ}$ incidence angle.

surface roughness. At the intermediate wavelengths (1.4 and $1.7 \mathrm{~cm}$ ), the radiance is less affected by the surface and more information is obtained on the internal characteristics of the snowpack. All of the above generalizations apply to snow conditions encountered by various satellite observations for different regions of the world.

The presence of liquid water content in a snowpack completely changes the observed microwave signatures (Chang and Shiue 1980; Mätzler and others 1980; Stiles and Ulaby 1980). A few per cent of liquid water in snow will cause a sharp increase in the brightness temperature (Chang and Gloersen 1975). This is because the emission of a small amount of liquid water within the snowpack alters the emitting radiance of dry snow.

The condition of the ground beneath the snow determines the intensity of the radiation emitted from below. Dry or frozen ground has a high emissivity (0.9 0.95 ) whereas unfrozen wet ground has a much lower emissivity (0.7). Knowledge of the condition of ground is important for the interpretation of observed brightness temperature of a shallow snowpack. The difference of vertical and horizontal polarized brightness temperature at $2.8 \mathrm{~cm}$ wavelength could reflect the frozen and thawed soil condition under a shallow snowpack.

\section{SNOW-PARAMETER RETRIEVAL ALGORITHM}

Kunzi and others (1982) reported an algorithm to retrieve snow cover parameters using the Nimbus-7 SMMR data. The brightness temperature gradients of 37 and $18 \mathrm{GHz}$ were used to discriminate snow parameters. The snow water equivalent relationship was derived from the regressing brightness gradient and the measured snow water equivalent. Based on the SMMR data for the 1978-1979 winter season, encouraging results were obtained. Chang and others (1982) reported snow parameter retrieval results based on a theoretically derived algorithm and the results compared favorably with snow data taken from Eurasia and the Canadian high plains. These relationships will be used for the snow parameter retrieval algorithm used in this study. The snow depth-brightness temperature relationship for a uniform snow field can be expressed as follows (Chang 1986):

$$
\mathrm{SD}=1.59 *\left(\mathrm{~T}_{18 \mathrm{H}}-\mathrm{T}_{37 \mathrm{H}}\right) \mathrm{cm}
$$

where $\mathrm{T}_{18 \mathrm{H}}$ and $\mathrm{T}_{37 \mathrm{H}}$ are the brightness temperature at 18 and $37 \mathrm{GHz}$ horizontal polarization. This equation was derived from linearly fitting the data shown in Fig.1 assuming a snow density of $0.3 \mathrm{Mg} / \mathrm{m}^{3}$ and its application should be limited to snow depths less than 1 meter. Since the snow within a SMMR footprint $(25 \mathrm{~km} \times 25 \mathrm{~km})$ can be quite variable, pixels with derived snow depth less than $2.5 \mathrm{~cm}$ will be assigned as no snow. The snow covered area is defined where derived snow depth is thicker than $2.5 \mathrm{~cm}$.

\section{INTERCOMPARISON OF SMMR-DERIVED SNOW MAPS} AND OTHERS

Snow cover maps are routinely produced by the National Environmental Satellite Data and Information Service of the National Oceanic and Atmospheric Administration (NOAA/NESDIS) and by the U.S. Air Force Global Weather Center (USAFGWC). NESDIS monitors continental snow cover extent using NOAA satellites on a weekly basis (Dewey and Heim 1981). Skilled analysts hand prepare the snow cover chart based on imagery information. The Air Force charts rely on snow depth reported by weather stations. A complex computer program is then used to extrapolate the point measurements to area snow coverage. Kukla and Robinson (1981) reviewed the accuracy of these two products. Table I shows the variation and differences between them for the Northern Hemisphere snow covered area for the year of 1979. The snow covered area derived by NESDIS varied from 49.3 million $\mathrm{km}^{2}$ in the 1978 winter season to 4.2 million $\mathrm{km}^{2}$ in the summer of 1979. The differences between NESDIS and Air Force products are substantial in the fast-changing fall season. For example, in the 45th week of 1979, a difference of 12.5 million $\mathrm{km}^{2}$ was observed between these two products. The major differences are in Europe and Asia (Fig.2). Persistent cloud cover probably was probably the reason for the differences.

A six-year snow cover/snow depth data set has been produced using Nimbus-7 SMMR data. It covers the period 
TABLE I. NORTHERN HEMISPHERE SNOW-COVERED AREA COMPARISON FOR 1979 (UNITS: MILLIONS $\mathrm{KM}^{2}$ )

$\begin{array}{rrrc}\text { Week No. } & \text { NOAA } & \text { AF } & \text { NOAA-AF } \\ 1 & 48.4 & 47.3 & 1.1 \\ 5 & 49.3 & 47.6 & 1.7 \\ 10 & 45.3 & 42.4 & 2.9 \\ 14 & 38.0 & 34.9 & 3.1 \\ 18 & 28.7 & 20.5 & 8.2 \\ 23 & 17.3 & 7.9 & 9.4 \\ 27 & 7.1 & 2.2 & 4.9 \\ 31 & 5.8 & 4.2 & 1.6 \\ 36 & 4.2 & 5.0 & -0.8 \\ 40 & 12.7 & 18.6 & -5.9 \\ 45 & 24.1 & 36.6 & -12.5 \\ 49 & 35.1 & 38.5 & -3.4\end{array}$

of November 1978 to October 1984. Snow parameters were derived based on Equation (1) using calibrated SMMR brightness temperatures. Fig. 3 shows a sample SMMR snow map (February 1983). In order to compare the different snow maps, both NESDIS and USAFGWC maps were projected onto a one degree by one degree SMMR map grid. Generally the major snowfield features matched well with those of NESDIS snow cover maps except in very shallow snow covered areas. Due to this limitation, total snow covered area derived from SMMR is usually about $10 \%$ less than the other two products. Fig. 4 shows a typical

\section{NESDIS AND USAFGWS SNOW MAP COMPARISON (1979 DAY 315/WEEK 45)}

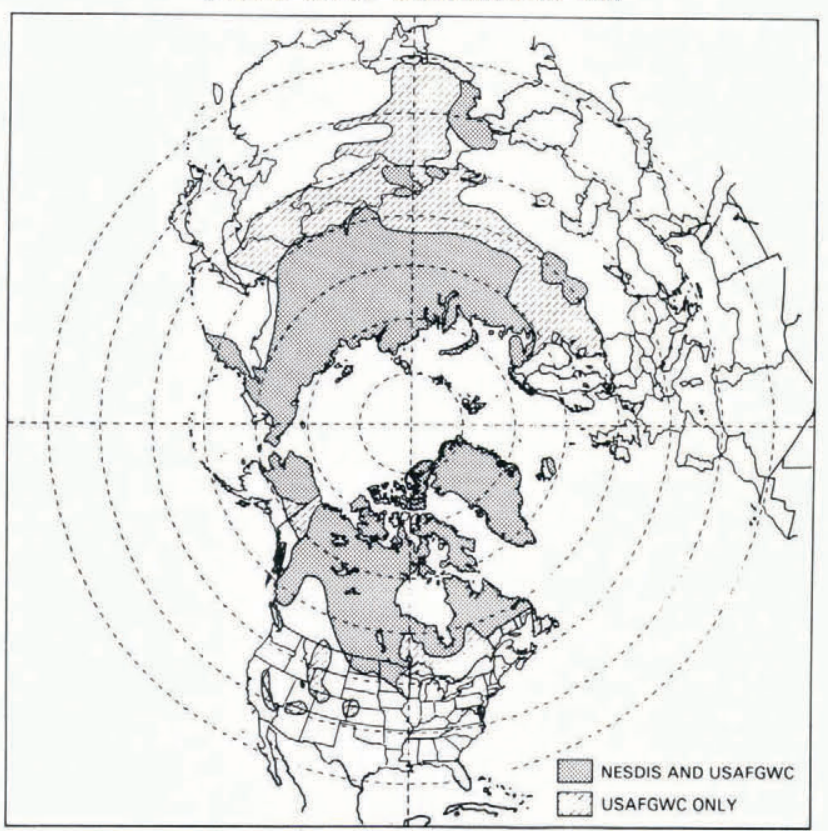

Fig.2. Differences in NESDIS and USAFGWC snow cover map (November 1979).

\section{NIMBUS-7 SMMR DERIVED SNOW DEPTH MAP FEBRUARY, 1983}

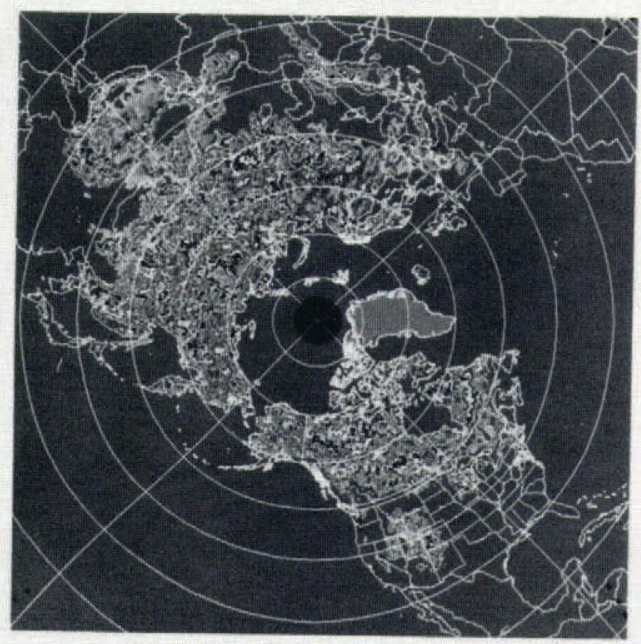

SNOW DEPTH $1.59 \times\left(T_{18 H}-T_{37 H}\right) \mathrm{cm}$

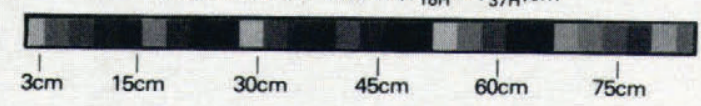

Fig.3. SMMR-derived snow map (February 1983). (Also reproduced in colour in appendix at end of volume.)

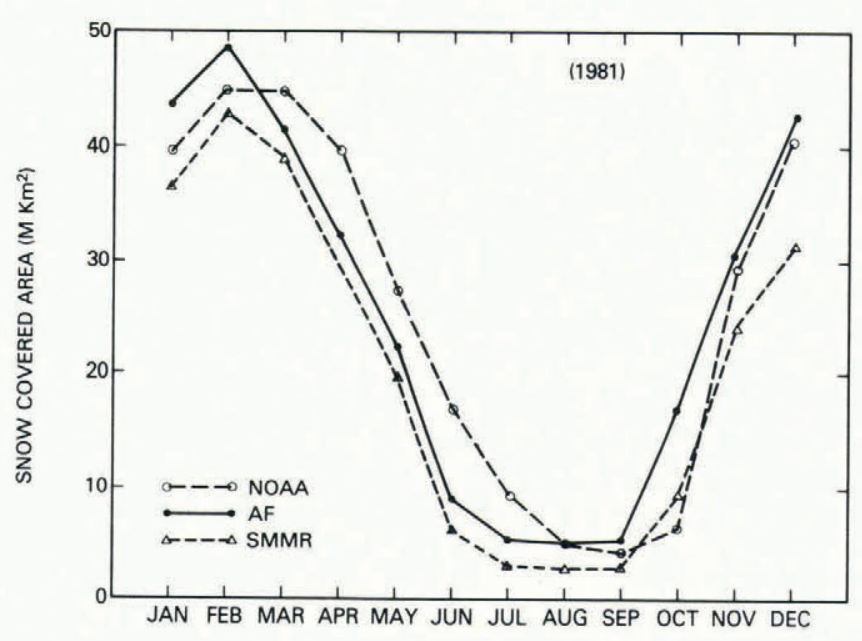

Fig.4. Comparisons of weekly snow covered area derived by NESDIS, USAFGWC and SMMR for 1981.

comparison of the Northern Hemisphere snow covered areas derived from these three methods for each month of 1981.

In order to make a preliminary evaluation of the accuracy of these products, the continental United States was chosen as the test area. The snow depths reported by weather stations were used as the reference point measurements. A subjective analysis similar to those used in the meteorological data analysis was performed to draw the snow covered area. Then the NESDIS and SMMR snow boundary lines were overlaid on the same chart. The snow cover maps for mid-January and mid-February of 1983 were chosen for comparison (Figs 5 and 6). In the western US, all three products gave very similar results for both January and February. Due to deeper snow conditions, mountainous terrain did not seem to affect the snow boundary determination. The January snow cover in the eastern US was very sparse and shallow. Only a small area in New England showed in the SMMR snow map. This is probably because the heavier vegetation cover and denser 


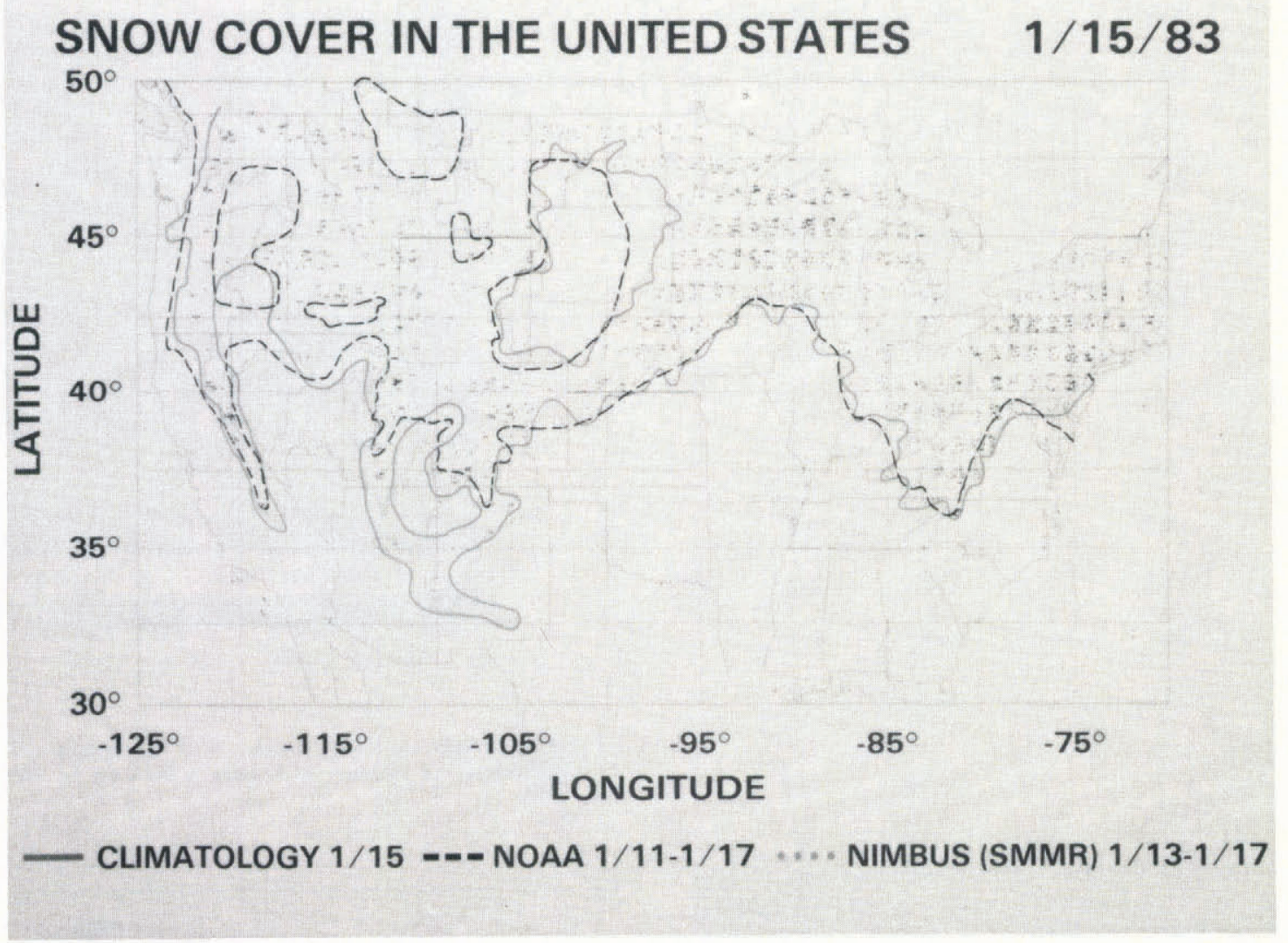

Fig.5. Comparisons of National Weather Stations reported snow depth with NESDIS and SMMR snow covered area, mid-January 1983.

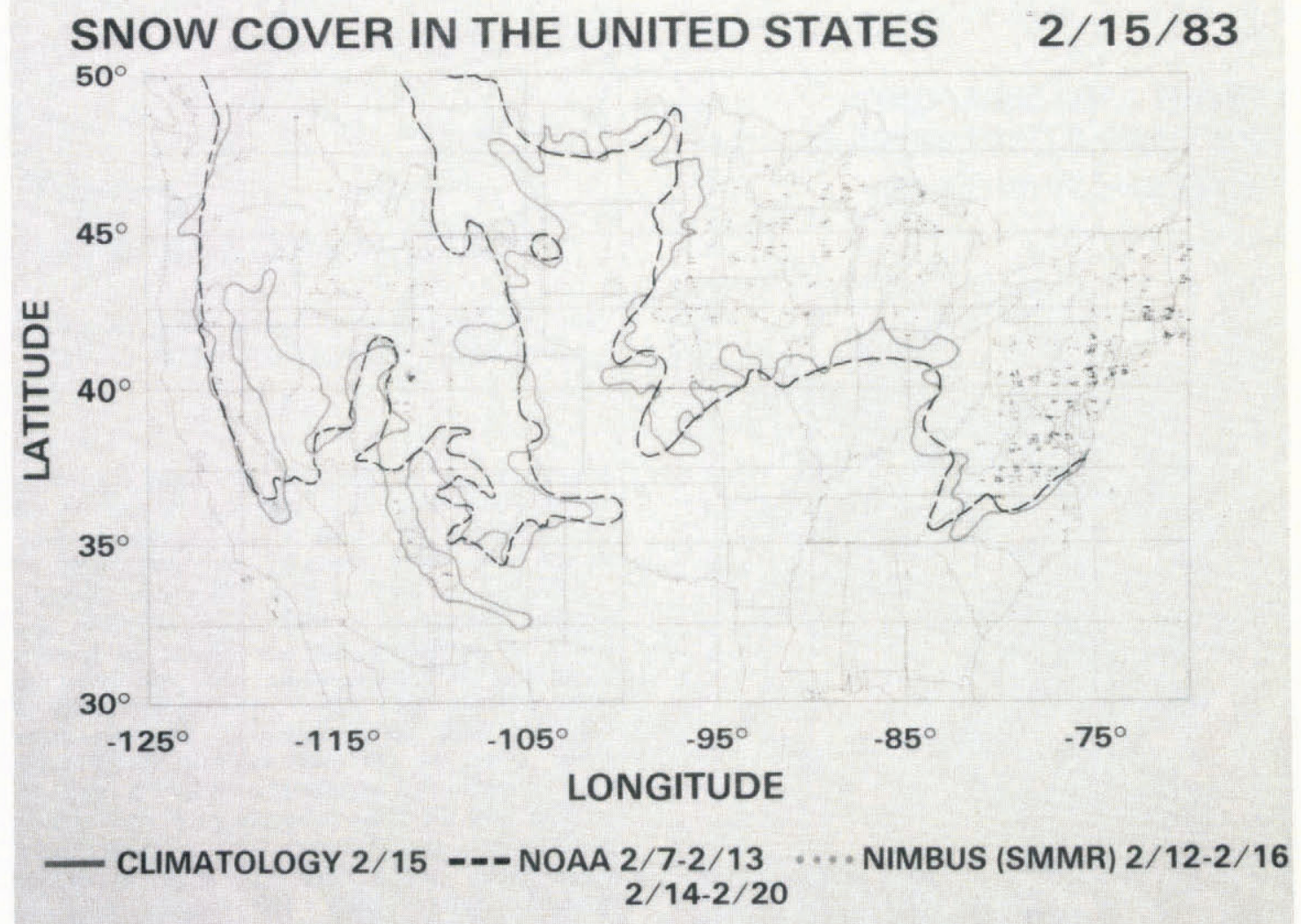

Fig.6. Comparisons of National Weather Stations snow depth with NESDIS and SMMR snow covered area, mid-February 1983. 
urban development in the eastern US masked out the microwave signatures. The threshold for snow/no-snow discrimination needs adjustment for this area. But in February the SMMR map matched better in the eastern US, because there was more snow on the ground. The southernmost snow boundary is nearly always slightly different in each map and the presence of shallow and patchy snow probably is the reason. No effort was made to compare the derived snow depth and those reported by weather stations.

\section{CANADIAN HIGH PLAINS AND RUSSIAN STEPPES}

Rango and others (1979) reported good correlations for brightness temperature and snow depth over the Canadian high plains using Nimbus-5 and Nimbus-6 Electrically Scanned Microwave Radiometer (ESMR) data. Chang and others (1982) reported similar results for the Russian steppes and the Canadian high plains. The vegetation, topography, climate and latitude in these two areas are comparable. The vegetation is predominantly a variety of grasses and the topography is generally flat. Both areas experience very cold winters with snow covering the ground from December through March. Air temperatures for the study areas, before and after satellite passes, were below $0^{\circ} \mathrm{C}$ with little chance of significant melting; dry snow conditions were assumed. Regression from both test sites is significant at the 0.005 level with $R^{2}$ values of 0.75 for Russian and 0.81 for Canadian sites using only the $37 \mathrm{GHz}$ vertically polarized brightness temperatures (Fig.7). Due to lack of snow water equivalent data for large area comparisons, snow depth information was utilized. A snow density of $0.3 \mathrm{Mg} / \mathrm{m}^{3}$ was assumed to relate the snow depth to snow water equivalent. The data displayed considerable scatter, which is probably due to inhomogeneity within each footprint. The theoretically calculated brightness curve for a mean snow grain radius of $0.35 \mathrm{~mm}$ fits well with the observed conditions. Snow depth and snow water equivalent for these areas could be inferred from microwave brightness temperatures measured by the SMMR spaceborne sensors.

\section{COLORADO RIVER BASIN STUDY}

In 1983 the snowfall for the Colorado River basin was well above average. Serious flooding in the western US was predicted for the spring melting season. A cooperative project between the US Geological Survey and the National Aeronautics and Space Administration was set up to explore the potential of using passive microwave data for determining snowpack properties in this mountainous region.
In order to analyze the relationship between microwave brightness temperature and snow parameters, a common geographical grid was established to register all the available information, which includes elevation, slope, vegetation type, vegetation cover amount, snow course data, climatology data and SNOTEL data. The mesoscale footprint of the SMMR, an ellipsoid of approximately $40 \mathrm{~km} \times 50 \mathrm{~km}$ for the $18 \mathrm{GHz}(1.7 \mathrm{~cm})$ radiometer, complicates the determination of snow water equivalent from microwave radiances in the mountainous regions. The $R^{2}$ between $T_{B}$ and snow depth for a $1 / 4^{\circ} \times 1 / 4^{\circ}$ grid usually is only about 0.5 because of the difficulty in making the comparison between a point surface measurement and a mesoscale measurement from space. Analysis is now being concentrated on combining geographical information and microwave information to develop a better snow parameter retrieval algorithm for use in the mountainous regions.

\section{ALASKA STUDY AREA}

In northern Alaska the difference between the soil temperature and the air temperature can be as large as $40^{\circ} \mathrm{C}$. This steep temperature gradient in the snowpack promotes metamorphism and the formation of depth hoar crystals. The crystal size of depth hoar is usually larger than that of new snow crystals. Lower brightness temperatures were observed by the Nimbus-7 SMMR in this area, typically with a snowpack of $30-50 \mathrm{~cm}$ in depth, and can be explained by radiation interacting with a depth hoar layer (Hall and others 1986). In order to develop a retrieval algorithm for this area, information on the history of the thickness of the depth hoar layer and the characteristic grain size is needed. Based on this information and a snow energy and mass balance model, physical properties of the snowpack can be estimated.

\section{DISCUSSION}

Six year Nimbus-7 SMMR derived Northern Hemisphere snow parameter maps have been produced using a simple algorithm. The snow boundary lines derived by NESDIS, USAFGWC and SMMR were compared. Normally, the SMMR derived snow boundary maps showed less snow than those of the NESDIS and the USAFGWC snow maps. This is because microwaves can penetrate through a shallow snowpack without registering a noticeable scattering effect. However, when the microwave signatures indicate snow, the entire field of view is probably snow covered. Over the mountainous area, terrain effects tend to modify the microwave signatures. The sensitivity of microwave radiation
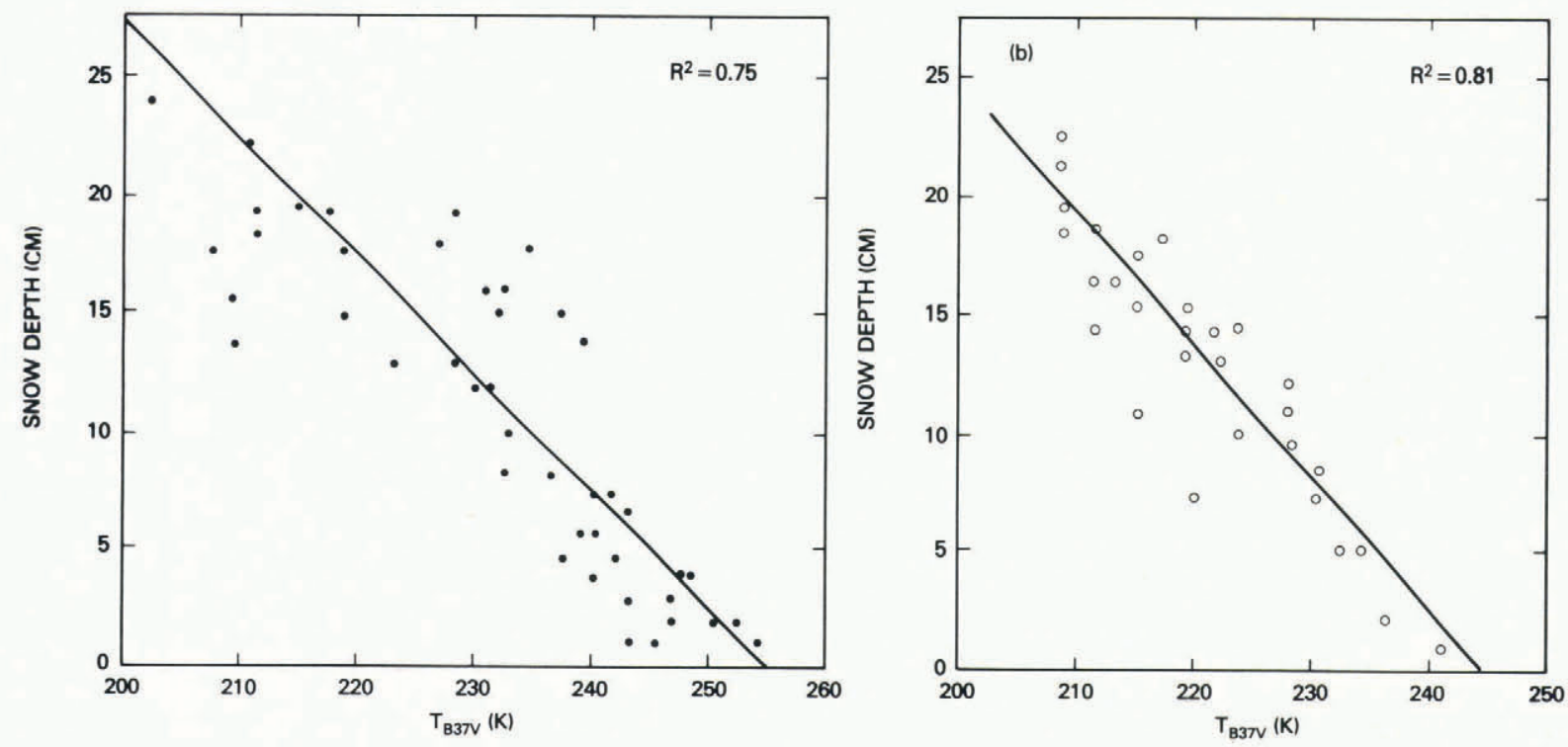

Fig.7. SMMR brightness temperature versus snow water equivalent for (a) Russian steppes, 15 February 1979 and (b) Canadian High Plains, 12 February 1983. 
with respect to snow depth will be reduced, but the snow boundary can still be delineated. For heavily vegetated areas, the sensitivity of microwaves for detecting snow will also be reduced. The vegetation effect can be predetermined and classified by using visible and infrared imagery data. The depth hoar layer within a snowpack will greatly alter the microwave signatures. By taking into account all these factors, different algorithms will be developed to account for different snow conditions.

To evaluate the quality of retrieved snow water equivalent from passive microwave data, several areas were chosen for comparison. The best results were found in the Canadian high plains and the Russian steppe areas. The $\mathrm{R}^{2}$ for these uniform and homogeneous areas are typically between 0.75 and 0.8 . The results from mountainous areas, forested areas and snowpacks with depth hoar layers are not as good. The $\mathrm{R}^{2}$ for these areas usually is only about 0.5 or less. Different algorithms are required to retrieve the snow parameters in these regions. Further tests are required before regional algorithms can be used in combination for global operational purposes.

\section{REFERENCES}

Chang A T C 1986 Nimbus-7 SMMR snow cover data. Glaciological Data. Report GD-18: 181-187

Chang A T C, Gloersen P 1975 Microwave emission from dry and wet snow. In Rango A (ed) Operational applications of satellite snowcover observations. Washington, DC, National Aeronautics and Space Administration: 399-407 (NASA Special Publication 391)

Chang A T C, Shiue J C 1980 A comparative study of microwave radiometer observations over snowfields with radiative transfer model calculations. Remote Sensing of Environment 10(3): 215-229

Chang A T C, Gloersen P, Schmugge $T \mathrm{~J}$, Wilheit $\mathrm{T}$, Zwally H J 1976 Microwave emission from snow and glacier ice. Journal of Glaciology 16(74): 23-39

Chang A T C, Foster J L, Hall D K, Rango A, Hartline B K 1982 Snow water equivalent estimation by microwave radiometry. Cold Regions Science and Technology 5(3): 259-267

Dewey K F, Heim R Jr 1981 Satellite observations of variations in northern hemisphere seasonal snow cover. NOAA Technical Report NESS 87

Foster J L, Rango A, Hall D K, Chang A T C, Allison L J, Diesen B C III 1980 Snowpack monitoring in North America and Eurasia using passive microwave satellite data. Remote Sensing of Environment 10: 285-298

Gloersen P, Barath F T 1977 A scanning multichannel microwave radiometer for Nimbus-G and Seasat-A. IEEE Journal of Oceanic Engineering 2: 172-178

Hall D K, Chang A T C, Foster J L 1986 Detection of the depth-hoar layer in the snow-pack of the Arctic coastal plain of Alaska, U.S.A., using satellite data. Journal of Glaciology 32(110): 87-94

Kukla G, Robinson D 1981 Accuracy of operational snow and ice charts. IEEE International Geoscience and Remote Sensing Symposium '81: 974-987

Kunzi K F, Patil S, Rott H 1982 Snow-cover parameters retrieved from Nimbus-7 Scanning Multichannel Microwave Radiometer (SMMR) data. IEEE Transactions on Geoscience and Remote Sensing GE20: 452-467

Matson M, Ropelewski C F, Varnadore M S 1986 An atlas of satellite-derived northern hemispheric snow cover frequency. Washington, DC, US Department of Commerce

Mätzler C, Schanda E, Hofer R, Good W 1980 Microwave signatures of the natural snow cover at Weissfluhjoch. Washington, DC, National Aeronautics and Space Administration: 203-223 (NASA Conference Publication 2153)

Rango A (ed) 1975 Operational applications of satellite snowcover observations. Washington, DC, National Aeronautics and Space Administration (NASA Special Publication 391)

Rango A 1978 Pilot tests of satellite snowcover/runoff forecasting systems. Proceedings of the Western Snow Conference, 46th annual meeting: 7-14
Rango A, Chang A T C, Foster J L 1979 The utilization of spaceborne microwave radiometers for monitoring snowpack properties. Nordic Hydrology 10(1): 25-40

Stiles W H, Ulaby F T 1980 Microwave remote sensing of snowpacks. Washington, DC, National Aeronautics and Space Administration (NASA Contractor Report 3263) 